\title{
The Educators' Datafied Present and Future: Complexity as an Approach to Developing Educators' Data Literacies
}

Juliana E. Raffaghelli

Faculty of Psychology and Education

Open University of Catalonia

Bonnie Stewart

Faculty of Education

University of Windsor

\section{Correspondence:}

Juliana E. Raffaghelli

Open University of Catalonia (Faculty of

Psychology and Education)

Email: jraffaghelli [at] uoc.edu

\begin{abstract}
In the higher education context, an increasing concern on the technical or instrumental approach permeates attention to academics' data literacies and faculty development. The need for data literacy to deal specifically with the rise of learning analytics in higher education has been raised by some authors, though in spite of some focus on the need to develop academics' data literacy to embrace fair practices, this literature is often also rooted in a technical or data-driven perspective. In this paper, the authors summarize an empirical study based on 137 articles using the terms "data literacy," "teachers," and "faculty development," spanning from 2014 and 2019. The findings point out that out of the total, 78 papers reviewed took an instrumental, data science-focused perspective on data literacy, were the technical abilities like extracting data and interpreting or reporting appropriately (authors, in press). Data safety and effective data management perspectives accounted for another 35 of the 137 articles. Only seven took up data literacy from a critical perspective, while only five looked at the pedagogical practice. These preliminary findings require awareness and discussion on the light of appropriate faculty development approaches and activities. We introduce some recommendations aimed at understanding data as a complex emerging phenomenon in our societies, which requires building the literacies to face their negative effects like data surveillance and algorithmic biases, but also, to uncover its emancipatory power.
\end{abstract}

Keywords: data literacy, educators, faculty development, complexity 


\section{Introduction}

Digital technologies and data systems are increasingly pervasive in contemporary society. From "smart" thermostats through web tracking and the analytics collected by institutional content management systems, datafication capacity surrounds us in daily life, in higher education, and beyond. Our knowledge-making and knowledge-dissemination systems are among those rifest with datafication implications (Williamson, 2018). But do those of us who work in knowledge production and so-called higher learning understand these implications?

The rise of big data, machine learning, and Artificial Intelligence (AI) have sometimes been characterized as positive developments (Townsend, 2013). However, concerns regarding surveillance, bias, and exclusion connected to data-driven practices are beginning to emerge in scholarship (Gilliard \& Culik, 2018; Noble, 2018; Zuboff, 2015;) and in popular media (Brown, 2017; Schwab, 2019). These concerns raise questions about the role of higher education in fostering critical approaches to knowledge production, in a time when our institutional systems, from registration platforms through learning environments, are profoundly datafied. Against this backdrop, our paper frames the issue of educators' data literacies and data literacy development. We overview our research into how the concept of data literacy circulates in contemporary literature and explore paths towards development of more complex and critical understandings of datafication among educators.

\section{The Educators' Datafied Present}

There are a growing number of studies on educators' data literacies, predominantly in the K-12 context. The majority of these focus on teachers' skills in dealing with school data, particularly from a technical or performance management perspective (Dunlap \& Piro, 2016; Hoogland et al., 2016; Mandinach \& Gummer, 2016). The "data-driven" decision-making and workflows that emerge from this tradition tend to frame data literacy as the ability to collect or extract educational data to support institutional decisions regarding students (Hartong \& Förschler, 2019).

In the higher education context, this same technical or instrumental approach permeates attention to academics' data literacies and faculty development. The need for data literacy to deal specifically with the rise of learning analytics in higher education has been raised by some authors (Persico \& Pozzi, 2015; Wasson et al., 2016), though in spite of some focus on the need to develop academics' data literacy to embrace fair practices (Tsai \& Gasevic, 2017), this literature is often also rooted in a technical or data-driven perspective.

The authors' 2019 empirical study of 137 articles using the terms "data literacy," "teachers," and "faculty development" found that 78 of the papers reviewed took an instrumental, data sciencefocused perspective on data literacy, focused on technical abilities like extracting data and interpreting or reporting appropriately (Raffaghelli \& Stewart, 2020). Data safety and effective data management perspectives accounted for another 35 of the 137 articles. Only seven took up data literacy from a critical perspective, while only five looked at the pedagogical possibilities and implications of data in education.

The dominant technical approach to educators' data literacies, then, reflects an important gap in preparing higher education to deal critically with datafication. The literacies required for educators to thrive in datafied professional contexts seem to demand broader epistemological 
frameworks than a technical, instrumentalist focus on performance management, efficiencies, or evidence can offer. As Fenwick and Edwards (2016) have suggested, the dominant technicallyfocused framing reconfigures professional practice and responsibility without adequately addressing the implications this holds for professional learning. Therefore, the authors of this paper present an alternate conceptual framework for data literacy which introduces a complicated/complex distinction (Raffaghelli \& Stewart, 2020). This conceptualisation, based in Snowden and Boone's (2007) Cynefin framework, offers a means to distinguish technical and instrumental approaches to datafication from critical ones. A focus on complexity helps us develop an emergent yet strategic path for developing educators' literacies for dealing with datafication as critical professionals.

"Cynefin" translates from the Welsh as "habitat," broadly, and focuses on ecological, relational understandings of environment and domain. As a framework, Cynefin identifies five domains for decision-making, each representing a different type of ecosystem for problem-solving based on variant cause-effect patterns. The two key domains for our purposes are the complicated domain and the complex domain. The distinction between the two hinges primarily on the relationship between cause and effect. In the complicated domain, there are multiple right answers or paths toward right answers, and clear-if not always visible-relationships between cause and effect, whereas in the complex domain, solutions are emergent, and cause and effect may only be identifiable in hindsight. The complicated domain is what Snowden and Boone (2007) called the realm of "known unknowns," where established paths to solutions can be identified, at least by experts. In the complex domain, however, patterns are not as replicable: this is the realm of "unknown unknowns," where predictable right answers have been exchanged for flux and uncertainty. Complexity is an emergent domain wherein the predictability that expertise is based in is no longer a reliable construct, and in which a "probe, sense, respond" approach to problem-solving is demanded.

Narratives surrounding datafication often draw on the certainty and measurability of known unknowns-or the realm of the complicated_for their appeal and power, as it emerges in the recently advertised MIT course in machine learning is headlined "Machine Learning Diminishes Uncertainty: Harvest its Power." This title features the promise of order and right answers being superimposed on the messy complexity of contemporary life. However, many aspects of lifeand of datafication itself-are unknown unknowns and restricting what counts as relevant to factors that are knowable means that complex realities get erased from view. This can have detrimental impacts on the individuals who embody and live those complex realities and has significant equity implications for society and for higher education.

\section{Re-Imagining the Profession: Beyond the Educators' Datafied Future}

The premise of our complexity framework is that higher education as a field would benefit from active efforts to develop educators' critical and complexity-oriented data literacy practices. This envisioned epistemology for data practices will require faculty engagement and activism, more than traditional "faculty development." A reality of the emerging sphere of datafication is that educators and learners continually encounter new technologies, practices, and systems, some of which may not even make themselves visible to us as they become embedded in our worlds. As a result, our capacity to make meaning within these systems and via their attendant practices and technologies will require us to go beyond the development of any specific technical skills. Traditional training or faculty development approaches, focused on discrete skills, will not suffice. Rather, data literacies based in critical understanding, complexity, and activism will require efforts in scholarship and communications, connecting the silos of research, 
teaching, and public communications. For example, the paradigm of Open Science, which invites citizens to explore and contribute to the data collected by researchers, could build new connections through the use of open data for learning (Coughlan, 2019), as could the sharing of open practices.

In the context of OTESSA, we further carried out a workshop based on a prior scheme developed by the authors (Stewart \& Raffaghelli, 2019, 2020) and further expanded as methodological approach to faculty development in Raffaghelli (2022). We did not collect personal data from the participants ( $N=12$ connected and active) who came mostly from the Canadian context. We asked for their permission, in any case, to report a general account of the workshop results.

Our approach framed a variety practices and narratives from datafication, to spot the technical and distinguish it from what we consider data literacy and data activism from a complex, ethical, and political perspective (Raffaghelli, 2018; Raffaghelli et al., 2021). Our ultimate goal is to foster critical approaches to knowledge production among higher education professionals. The workshop was a participatory, crowdsourced approach to making sense of this emergent problem together. Centered around the complicated/complex distinction and the gaps in the research literature identified in our published research around data practices in higher education (Raffaghelli, 2021; Raffaghelli et al., 2021; Raffaghelli \& Stewart, 2020; Stewart, 2020; Stewart \& Lyons, 2021), we invited the participants in the session to share their own data perspectives and practices through brief, hands-on data visualization activities and a sense-making review and discussion. The session unfolded us follows:

- Initial information to generate a sense of curiosity;

- Self-diagnosis to capture insights and develop self-awareness;

- Technical instruments to engage with data as material expression, based on methods, jargon, technologies, practices, and knowledge within professional communities;

- Reflection connected with the participants' experiences and practice contexts based on the epistemologies of data. "What am I doing and why am I not working with data? Why am I engaged in this movement, or why am I not? Am I resisting the establishment, or am I trying survive within an unjust context of professional practice and personal life?"

- Exploration of the professional roles as educators and educational researchers: "If I behave in a certain way, to what extent am I providing a different vision to my students or to the participants of my educational research?"

- Representation of the reflection's outcomes through a quadrant graph as a conceptual tool. We represented data practices and narrative as "complicated" or "complex," labelling them and understanding which of those would require further exploration, understanding, and engagement as educators.

Our preliminary results were consistent with other workshops conducted by the authors (Stewart \& Raffaghelli, 2019, 2020). The straightforward examples as well as the conversation about the educators' choices relating platforms, apps, and loT devices were not always clearly connected to the opaque practices connected to biases which reproduce the power structure. Simple accounts about our experiences with algorithms (recommender systems) and Artificial 
Intelligence within social media; as well as the observation of how bias might work (the case of Alexa's submissive voice) were the basis to discuss around unthinkable effects for human beings. We considered hence that educational action taking might start from understanding human data-interaction in a post-digital context where the digital is not only embedded in our laptops or devices but is spread in the environments we live (Jandrić et al., 2018). Indeed, our examples raised a number of emotions, from concern to fascination, from fear to lose freedom to the acceptance of our limitation as educators to stop the technological snowball. As it has been recently pointed out, educational action requires urgently understanding algorithms and debunking algorithmic misconceptions (Zarouali et al., 2021). During the workshop it concretely appeared the need of exploring such misconception, that could be eradicated amongst educators, before preparing resources or activities to work in class.

As we documented in prior workshops (Stewart \& Raffaghelli, 2019), it was clear that digital platforms were part of the participant's life, though Artificial Intelligence in its advanced forms (the smart technologies) are yet to come. We also observed how digital environments and advanced data collection systems were rejected, in contrast with other cultural contexts explored through the authors' workshops (Europe and Spain, Raffaghelli, 2019; Raffaghelli et al., 2019).

While exploring the Cynefin framework, the educators showed great concern about the role of algorithms in education and in their students' life, particularly relating to what could be an "economy of attention." Consistently with the cited prior experiences, we also observed that "tech-savvy" participants felt more reliant on their own possibilities to "hack the system" and escape surveillance and control. There was an overall agreement on the need of generating alternative data infrastructures, a task that could actually start in education by using and teaching to use Open Source software and platforms.

Nonetheless, more agentic practices seem to require further awareness and technical skills to "hack the system" and a critical perspective that allows the more tech-savvy participants to understand the impacts of technological developments.

Overall, the final conclusion was that in any case the more feasible approach might be to generate spaces for a reflective practice as an educator, jointly with the students, regarding what is behind the platforms that we live by. And particularly the platforms we work with, to expand our and our students' degrees of freedom in the future, against the dystopic account spread in the media nowadays.

\section{Author's Contributions}

This paper is the result of joint collaboration between the authors since 2018. The authors have met monthly and have held personal onsite meetings (Barcelona, December 2019, Stewart visiting fellow) to write the cited Literature Review work and the workshop's methodology. Any of the elements in this piece is the result of this joint conversation and collaborative writing. The authors are listed in alphabetic order, meaning that both have the same responsibility and presence in authorship.

\section{Open Researcher and Contributor Identifier (ORCID)}

Juliana Elisa Raffaghelli (iD https://orcid.org/0000-0002-8753-6478 Bonnie Stewart iD https://orcid.org/0000-0001-9576-1037 


\section{Funding}

For JR, the research work was funded by the project "The Project "Professional learning ecologies for Digital Scholarship: Steps for the Modernisation of Higher Education," Spanish Ministry of Economy and Competitiveness, Programme "Ramón y Cajal" RYC-2016-19589.

\section{Ethics Statement}

The research activity was approved by the Ethics' Committees of both Universities. Moreover, informed consent was presented at the workshop, to authorize the publication of a summary of the activities and results with no reference to any specific comment or conversation held during the workshop.

\section{Conflict of Interest}

The authors do not declare any conflict of interest.

\section{References}

Brown, M. (2017, August 30). Math isn't biased, but big data is. Forbes Magazine. https://www.forbes.com/sites/metabrown/2017/08/30/math-isnt-biased-but-big-datais/\#6eb1f154d564

Coughlan, T. (2019). The use of open data as a material for learning. Educational Technology Research and Development, 1-28. https://doi.org/10.1007/s11423-019-09706-y

Dunlap, K., \& Piro, J. S. (2016). Diving into data: Developing the capacity for data literacy in teacher education. Cogent Education, 3(1). https://doi.org/10.1080/2331186X.2015.1132526

Fenwick, T., \& Edwards, R. (2016). Exploring the impact of digital technologies on professional responsibilities and education. European Educational Research Journal, 15(1), 117-131. https://doi.org/10.1177/1474904115608387

Gilliard, C. \& Culik, H. (2018). The new Pythagoreans. boundary2org. https://www.boundary2.org/2018/07/gilliard-culik/

Hartong, S., \& Förschler, A. (2019). Opening the black box of data-based school monitoring: Data infrastructures, flows and practices in state education agencies. Big Data \& Society, 6(1), 1-12. https://doi.org/10.1177/2053951719853311

Hoogland, I., Schildkamp, K., van der Kleij, F., Heitink, M., Kippers, W., Veldkamp, B., \& Dijkstra, A. M. (2016). Prerequisites for data-based decision making in the classroom: Research evidence and practical illustrations. Teaching and Teacher Education, 60, 377386. https://doi.org/10.1016/J.TATE.2016.07.012

Jandrić, P., Knox, J., Besley, T., Ryberg, T., Suoranta, J., \& Hayes, S. (2018). Postdigital science and education. Educational Philosophy and Theory, 50(10), 893-899. https://doi.org/10.1080/00131857.2018.1454000

Mandinach, E. B., \& Gummer, E. S. (2016). What does it mean for teachers to be data literate: Laying out the skills, knowledge, and dispositions. Teaching and Teacher Education, 60, 366-376. https://doi.org/10.1016/j.tate.2016.07.011

Raffaghelli, J. E. (2018). Educators' data literacy supporting critical perspectives in the context of a "datafied" education. In M. Ranieri, L. Menichetti, \& M. Kashny-Borges (Eds.), Teacher education \& training on ict between Europe and Latin America (pp. 91-109). Aracné. https://doi.org/10.4399/97888255210238

Raffaghelli, J. E. (2019). Notas de Trabajo en campo [Fieldwork notes; Workshop]. Sociedad Datificada y Educación. Más allá de la abundancia de datos, hacia una perspectiva 
crítica y constructiva. Universitat Oberta de Catalunya. [Datafied Society and Education: Beyond data abundance: towards a critical and constructive perspective] ]https://doi.org/10.5281/zenodo.4446763

Raffaghelli, J. E. (2021). "Datificazione" e istruzione superiore: Verso la costruzione di un quadro competenziale per una rinnovata Digital Scholarship [“Datafication and Higher Education: Building a competence framework for a renewed digital scholarship]. Excellence and Innovation in Learning and Teaching - Open Access, 0(0), 128-147. https://doi.org/10.3280/exioa0-2021oa11132

Raffaghelli, J. E. (in press). Educators' data literacy: Understanding the bigger picture. In L. Pangrazio \& J. Sefton Green (Eds.), Learning to live with datafication: Educational case studies and initiatives from across the world. Routledge.

Raffaghelli, J. E., Atenas, J., \& Havemann, L. (2019). Data activism as scholarly pursuit. Workshop Instruments and Results. Universitat Oberta de Catalunya. https://zenodo.org/record/3557431\#.YR4tclj7SUk

Raffaghelli, J. E., Grion, V., \& de Rossi, M. (2021). Data practices in quality evaluation and assessment: Two universities at a glance. Higher Education Quarterly, online first. https://doi.org/10.1111/hequ.12361

Raffaghelli, J. E., Kuhn, C., \& Berga, Q. (2021). Data Activism in higher education, a scholarly commitment. https://doi.org/10.5281/zenodo.5768143

Raffaghelli, J. E., \& Stewart, B. (2020). Centering complexity in 'educators' data literacy' to support future practices in faculty development: A systematic review of the literature. Teaching in Higher Education, 25(4), 435-455. https://doi.org/10.1080/13562517.2019.1696301

Noble, S. U. (2018). Algorithms of oppression: How search engines reinforce racism. NYU Press. https://doi.org/10.15713/ins.mmj.3

Persico, D., \& Pozzi, F. (2015). Informing learning design with learning analytics to improve teacher inquiry. British Journal of Educational Technology, 46(2), 230-248. https://doi.org/10.1111/bjet.12207

Schwab, K. (2019, January 6). IoT security is so bad, many companies can't tell when they're hacked. Fast Company. https://www.fastcompany.com/90292568/iot-security-is-so-badmany-companies-cant-tell-when-theyre-hacked

Snowden, D. J., \& Boone, M. E. (2007). A leader's framework for decision making. Harvard Business Review. https://hbr.org/2007/11/a-leaders-framework-for-decision-making

Stewart, B. (2020). The Open Page project. Journal of Teaching and Learning, 14(1), 59-70. https://doi.org/10.22329/jtl.v14i1.6265

Stewart, B. E., \& Lyons, E. (2021). When the classroom becomes datafied: A baseline for building data ethics policy and data literacies across higher education. Italian Journal of Educational Technology, online first. https://doi.org/10.17471/2499-4324/1203

Stewart, B., \& Raffaghelli, J. E. (2019). Workshop results: Datafication in education. How do we deal with digital systems? Universitat Oberta de Catalunya. https://doi.org/10.5281/zenodo.4453078

Stewart, B., \& Raffaghelli, J. E. (2020). Why should we care about datafication? Critical data literacies in Higher Education / Zenodo (pp. 1-16). OER2020 Conference - ALT. https://doi.org/10.5281/zenodo.3744135

Townsend, A. (2013). Smart cities: Big data, civic hackers, and the quest for a new utopia. Norton \& Co.

Tsai, Y.-S., \& Gasevic, D. (2017). Learning analytics in higher education --- Challenges and policies. In Proceedings of the Seventh International Learning Analytics \& Knowledge Conference on - LAK'17 (pp. 233-242). ACM Press.

https://doi.org/10.1145/3027385.3027400 
Wasson, B., Hansen, C., \& Netteland, G. (2016). Data literacy and use for learning when using learning analytics for learners. In S. Bull, B. M. Ginon, J. Kay, M. D. Kickmeier-Rust, \& M. D. Johnson (Eds.), Learning analytics for learners, 2016 workshops at LAK (pp. 38-41). CEUR. http://ceur-ws.org/Vol-1596/paper6.pdf

Williamson, B. (2018). The hidden architecture of higher education: building a big data infrastructure for the 'smarter university.' International Journal of Educational Technology in Higher Education, 15(1). https://doi.org/10.1186/s41239-018-0094-1

Zuboff, S. (2015). Big other: Surveillance capitalism and the prospects of an information civilization. Journal of Information Technology, 30(1), 75-89. https://doi.org/10.1057/jit.2015.5

Zarouali, B., Helberger, N., \& Vreese, C. H. de. (2021). Investigating Algorithmic Misconceptions in a Media Context: Source of a New Digital Divide? Media and Communication, 9(4), 134-144. https://doi.org/10.17645/mac.v9i4.4090 